\title{
Low-temperature growth of GaSb epilayers on GaAs (001) by molecular beam epitaxy
}

\author{
D. BENYAHIA ${ }^{1 *}$, Ł. KUBISZYN² ${ }^{2}$, K. MICHALCZEWSKI ${ }^{1}$, A. KĘBŁOWSKI ${ }^{2}$, P. MARTYNIUK ${ }^{1}$, \\ J. PIOTROWSKI ${ }^{2}$, and A. ROGALSKI ${ }^{1}$ \\ ${ }^{1}$ Institute of Applied Physics, Military University of Technology, ul. Gen. Kaliskiego 2, \\ 00-908 Warsaw, Poland \\ ${ }^{2}$ Vigo System S.A., ul. Poznańska 129/133., 05-850 Ożarów Mazowiecki, Poland
}

\begin{abstract}
Non-intentionally doped GaSb epilayers were grown by molecular beam epitaxy (MBE) on highly mismatched semi-insulating GaAs substrate (001) with 2 offcut towards [110]. The effects of substrate temperature and the Sb/Ga flux ratio on the crystalline quality, surface morphology and electrical properties were investigated by Nomarski optical microscopy, X-ray diffraction (XRD) and Hall measurements, respectively. Besides, differential Hall was used to investigate the hole concentration behaviour along the GaSb epilayer. It is found that the crystal quality, electrical properties and surface morphology are markedly dependent on the growth temperature and the group V/III flux ratio. Under the optimized parameters, we demonstrate a low hole concentration at very low growth temperature. Unfortunately, the layers grown at low temperature are characterized by wide FWHM and low Hall mobility.
\end{abstract}

Keywords: MBE, GaSb, GaAs, IR detectors.

\section{Introduction}

Antimonide-based compound semiconductors offer a wide range of band gaps, band gap offsets, and electronic barriers along with extremely high electron mobility and electron saturation velocity [1-3], and, therefore, enable a variety of extremely fast low-power electronic devices and infrared light sources [4,5]. Lattice-mismatched epitaxy of Sb-based materials on $\mathrm{GaAs}$ and $\mathrm{Si}$ substrates has attracted considerable attention due to the numerous advances in optoelectronic devices that can be enabled, including field effect transistors [6], infrared detectors [7], and semiconductor lasers [8]. While recent technical advancement has enabled high quality lattice matched GaSb epitaxy on native substrates, GaAs substrates are desirable for many applications due to its high quality with semi-insulating, large area, favourable thermal properties, excellent $\mathrm{n}$ and $\mathrm{p}$-type ohmic contacts and low cost. In addition, it affords the possibility of monolithic integration for optoelectronic devices. However, the high lattice mismatch between the GaSb epilayer and the GaAs substrate (7.8\%) complicates the growth of sophisticated device structures. To overcome the problem of this large lattice mismatch, which can lead to a big amount of threading dislocations and high defect density, various buffer layers such as compositionally graded metamorphic buffers $[9,10]$, low temperatures layers $[11,12]$, and superlattice layers [13] were proposed. Metamorphic buffers'

\footnotetext{
*e-mail: djalal.benyahia@wat.edu.pl
}

layers have been demonstrated in the growth of $\mathrm{AlGaAsSb}$ on GaAs [9] to achieve mid-infrared detectors and lasers. However, in this approach, initially the strain within the critical thickness is accommodated by a tetragonal distortion followed by defect formation and filtering, therefore, the necessity to grow thick buffer layers (often $>1 \mu \mathrm{m}$ ) is required. Moreover, metamorphic buffer layer approach exhibits several deficiencies such as the poor thermal and electrical conductivity, and the material degradation through the presence of threading dislocations. Recently, another technology, interfacial misfit dislocation (IMF) growth mode was developed [14,15], where the strain is relieved instantaneously at the mismatched heterointerface by the formation of a two-dimensional (2 D), periodic IMF arrays comprised of pure-edge $\left(90^{\circ}\right)$ dislocations along both [110] and [1-10] [14]. This growth mode offers a "buffer-free" approach with low threading dislocation density $\left(\sim 10^{5} \mathrm{~cm}^{-2}\right)$ [15].

In this paper, we investigate the influence of the growth temperature and the $\mathrm{Sb} / \mathrm{Ga}$ flux ratio on the crystal quality, the surface morphology and electrical properties of the $\mathrm{GaSb}$ epilayer grown on GaAs substrate.

\section{Experiment}

GaSb epilayers were grown on a semi-insulating GaAs (001) substrate with $2^{\circ}$ offcut towards [110] in a RIBER COMPACT 21 DZ solid-source molecular beam epitaxy (MBE) system, equipped with valved cracker for arsenic and antimony to produce $\mathrm{As}_{4}$ and $\mathrm{Sb}_{2}$, respectively. The 
manipulator thermocouple was used to monitor the substrate temperature. Growth temperature was calibrated from the GaAs oxide desorption temperature. After thermal desorption of oxide at $640^{\circ} \mathrm{C}$ under $\mathrm{As}_{4}$ overpressure, a 300-nm thick GaAs layer was grown at $640^{\circ} \mathrm{C}$ to obtain a smooth surface, with a growth rate of $0.93 \mu \mathrm{m} / \mathrm{h}$. Then, the substrate temperature was lowered to grow the GaSb layer. As shutter was left opened until the temperature of $580^{\circ} \mathrm{C}$ to protect the surface. Several $\mathrm{GaSb}$ layers were grown at growth temperature between $250^{\circ} \mathrm{C}$ and $540^{\circ} \mathrm{C}$ with $5 \mathrm{Sb} / \mathrm{Ga}$ flux ratio. After the optimization of the growth temperature, three $\mathrm{GaSb}$ layers were grown with a different $\mathrm{Sb} / \mathrm{Ga}$ flux ratio: 2.5, 5 and 12.5, respectively. The growth rate for a $\mathrm{GaSb}$ layer was $0.66 \mu \mathrm{m} / \mathrm{h}$, while the thickness was $2 \mu \mathrm{m}$ for 6 samples and $5 \mu \mathrm{m}$ for 4 samples. The growth process was monitored by in-situ reflection high-energy electron diffraction (RHEED).

The crystal quality of the samples was evaluated by a PANalytical X-ray diffractometer (XRD). The measurements were made in the $\omega$-direction. The electrical properties were characterized by Hall measurement using Van der Pauw method between $80 \mathrm{~K}$ and room temperature. Nomarski optical microscopy was used to evaluate the surface morphology.

\section{Results and discussion}

For all the samples, when the Sb shutter was opened, the RHEED pattern changed from a streaky of GaAs $(4 \times 2)$ to bright dots, corresponding to the transfer from a two-dimensional (2 D) to a three-dimensional (3 D) growth, being characteristic for Volmer-Weber growth mode [16]. After a few minutes, a clear two-dimensional RHEED $(1 \times 3)$ pattern was observed, as it is shown in Fig. 1, indicating a flat surface of GaSb layer.

Shiny mirror-like GaSb epilayers were grown at $250^{\circ} \mathrm{C}$ to $540^{\circ} \mathrm{C}$ temperature range with growth rate of $0.66 \mu \mathrm{m} / \mathrm{h}$ under optimized $\mathrm{Ga}$ and Sb fluxes [Fig. 2(a)]. Typically, the growth is much smoother for $2^{\circ}$ disoriented GaAs substrates. Rough not mirror-like looking surfaces were ob-

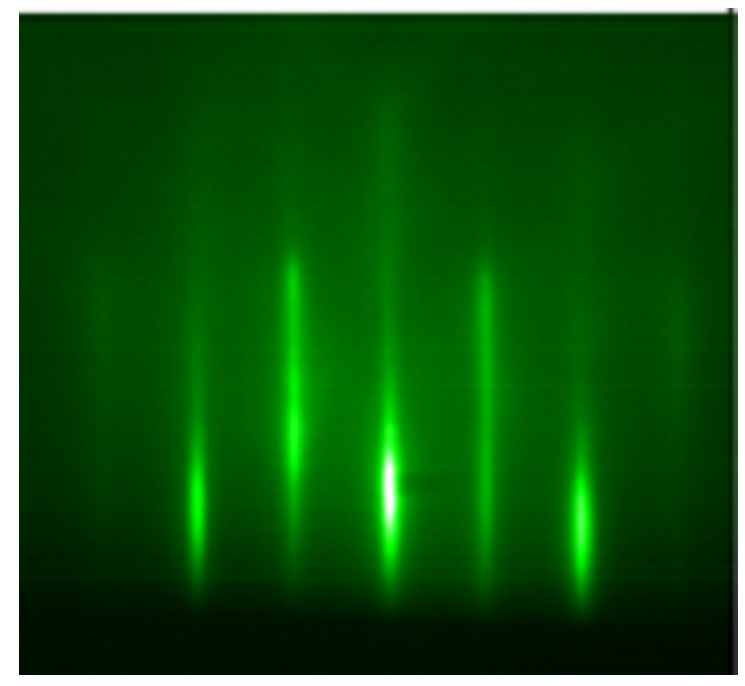

(a)

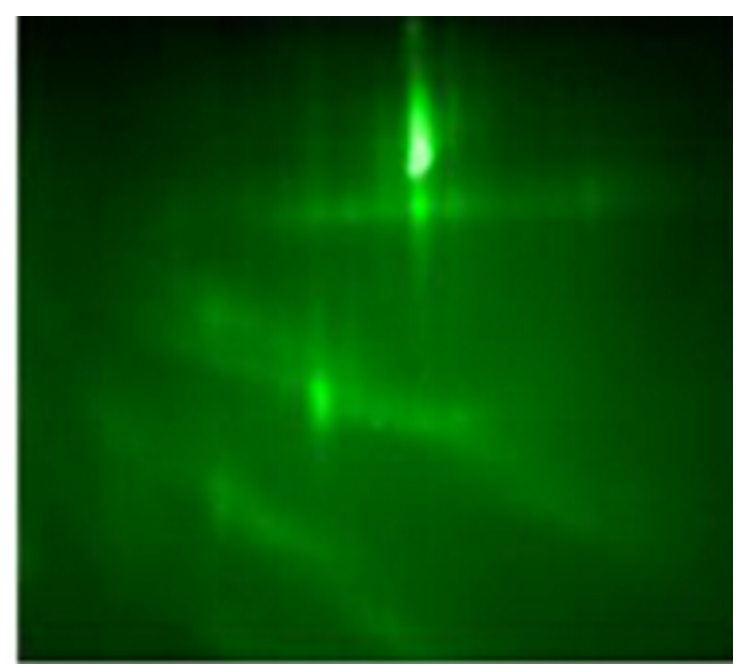

(b)

Fig. 1. GaSb layer RHEED patterns (a) (×1), (b) (×3).

tained in the attempts to grow outside some temperature and $\mathrm{Sb} / \mathrm{Ga}$ flux ratio ranges. Surface covered with fine Ga droplets [Fig. 2(b)] are typical for too low $\mathrm{Sb} / \mathrm{Ga}$ flux ratio.

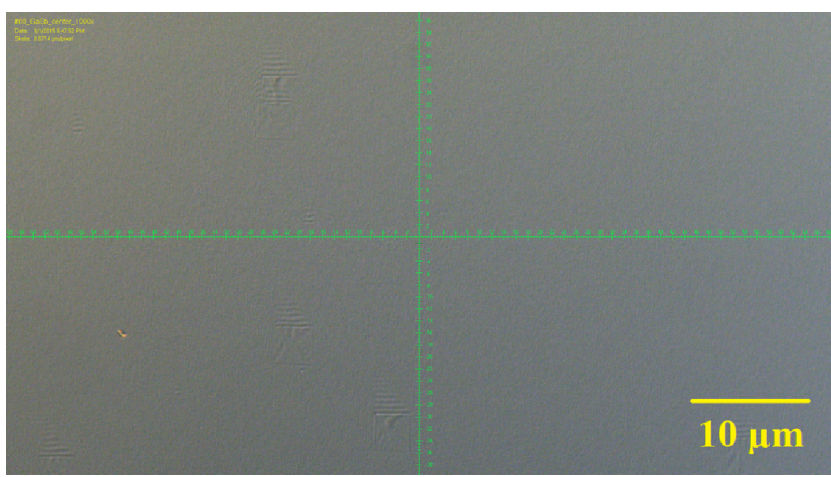

(a)

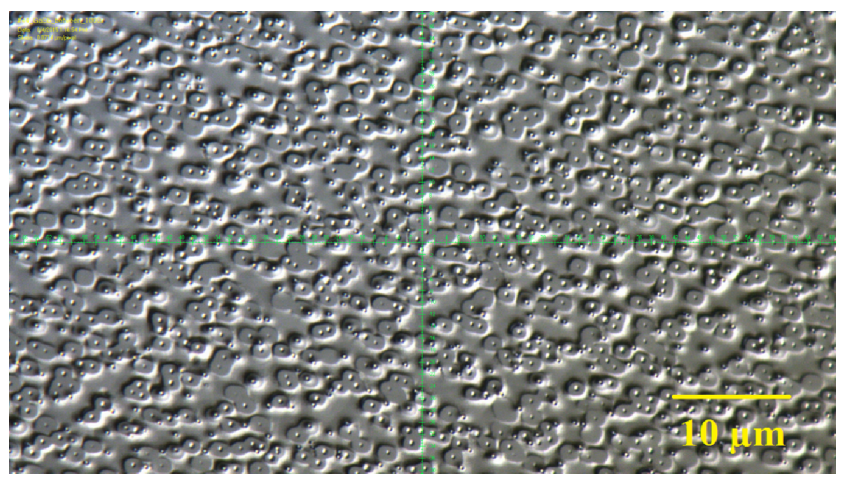

(b)

Fig. 2. Nomarski optical microscopy pictures with a magnification of 1000 of $2 \mu \mathrm{m}$ thick $\mathrm{GaSb}$ layer grown at $250^{\circ} \mathrm{C}$ for $5 \mathrm{Sb} / \mathrm{Ga}$ flux ratio (a) and at $475^{\circ} \mathrm{C}$ for $3 \mathrm{Sb} / \mathrm{Ga}$ fux ratio (b). 
Figure 3 shows the full width at half maximum (FWHM) of the GaSb layers in the $\omega$-direction as a function of growth temperature and with a $5 \mathrm{Sb} / \mathrm{Ga}$ flux ratio. The FWHM is significantly smaller for thicker layers and decreases with increasing growth temperature. This suggests a better crystal quality at high growth temperature and thicker sample.

The low crystalline quality of the samples grown at low temperatures is probably due to the formation of various extended defects, e.g., dislocations and microinclusions. This could be prevented by optimized growth conditions at the low temperature, namely reduced growth rate and smaller $\mathrm{Sb} / \mathrm{Ga}$ flux ratio.

FWHM as low as 110 arcsec was obtained for a $5-\mu \mathrm{m}$ thick layer grown at $490^{\circ} \mathrm{C}$. In the literature, A. Jallipalli et al. [17] reported FWHM of 194 arcsec and 20 arcsec of GaSb layers which thickness is of $0.5 \mu \mathrm{m}$ and $5 \mu \mathrm{m}$, respectively. On the other hand, Y. Li et al. [18] reported FWHM

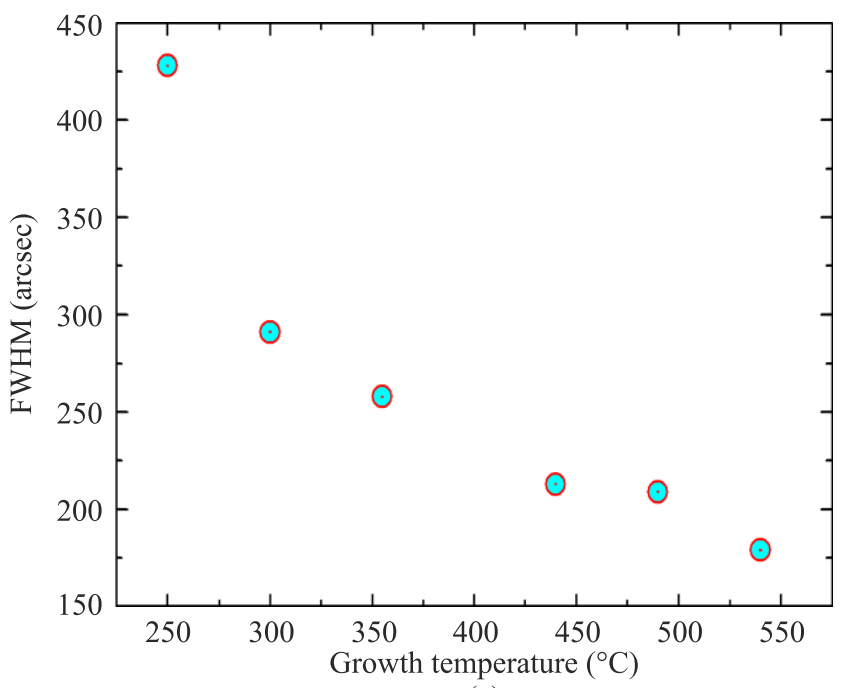

(a)

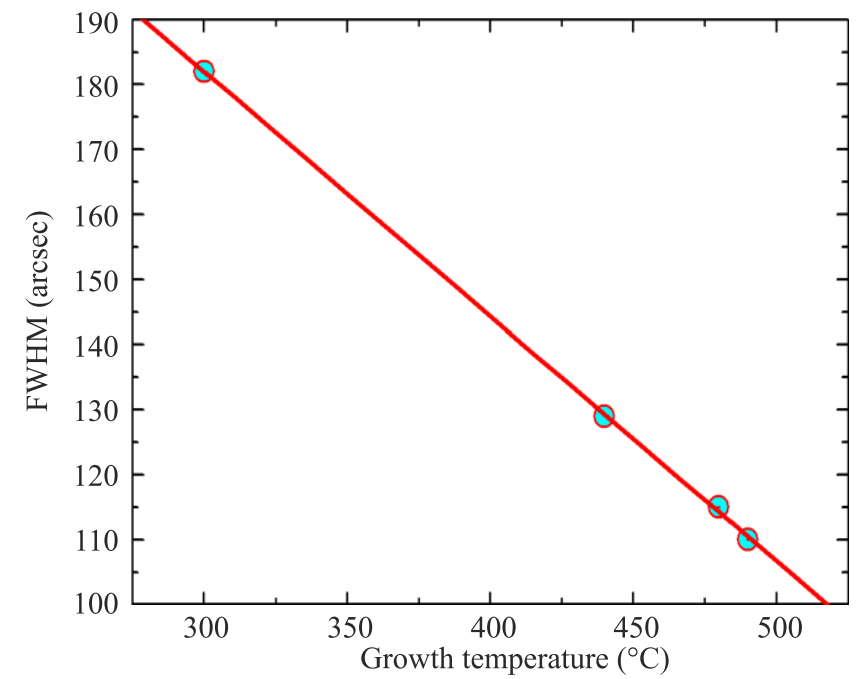

(b)

Fig. 3. FWHM of GaSb epilayers vs. growth temperature with a thickness of $2 \mu \mathrm{m}$ (a) and $5 \mu \mathrm{m}$ (b). of 160 arcsec for a GaSb layer with a $1 \mu \mathrm{m}$ thickness and a growth rate of $1 \mu \mathrm{m} / \mathrm{h}$.

As follows from Figs. 4, 5 and 6, all of the samples exhibited p-type conduction, being consistent with the results of Anayama et al. [19]. The hole mobility at room temperature weakly depends on growth temperature with an average of $560 \mathrm{~cm}^{2} / \mathrm{Vs}$ while at $80 \mathrm{~K}$, it increases from 493 $\mathrm{cm}^{2} / \mathrm{Vs}$ to $956 \mathrm{~cm}^{2} / \mathrm{Vs}$ as the growth temperature ramps from $250^{\circ} \mathrm{C}$ to $440^{\circ} \mathrm{C}$ (Fig. 4). When the growth temperature was higher than $440^{\circ} \mathrm{C}$, there was a significant decrease in hole mobility at $80 \mathrm{~K}$.

Both the room temperature and $80 \mathrm{~K}$ hole concentrations increase when the growth temperature of GaSb epilayers ramps (Fig. 4) due to native defects [20,21]. These p-type native defects include $\mathrm{Ga}$ antisite defect $\left(\mathrm{Ga}_{\mathrm{Sb}}\right)$ [22], $\mathrm{Ga}$ vacancy $\left(\mathrm{V}_{\mathrm{Ga}}\right)$ [23], and complex defect composed of a $\mathrm{V}_{\mathrm{Ga}}$ and $\mathrm{G} \mathrm{Ga}_{\mathrm{Sb}}$ [24]. Ga antisite is believed to be the main defect with concentration increasing with Ga-rich growth conditions. In fact, when the growth temperature increases, Sb atoms re-evaporate from the surface, therefore, the Sb lattice sites available for other atoms, especially $\mathrm{Ga}$, increase, which contributes to more Ga antisite.

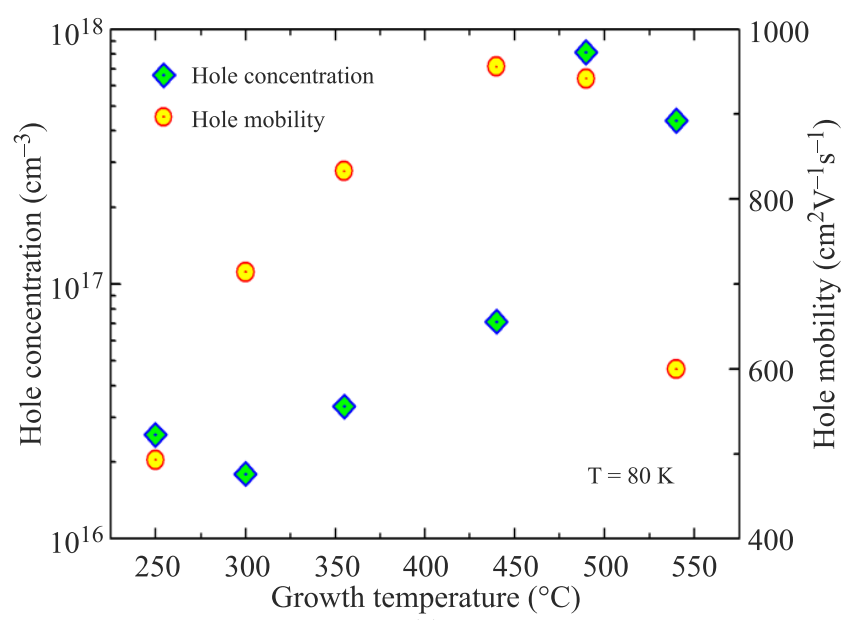

(a)

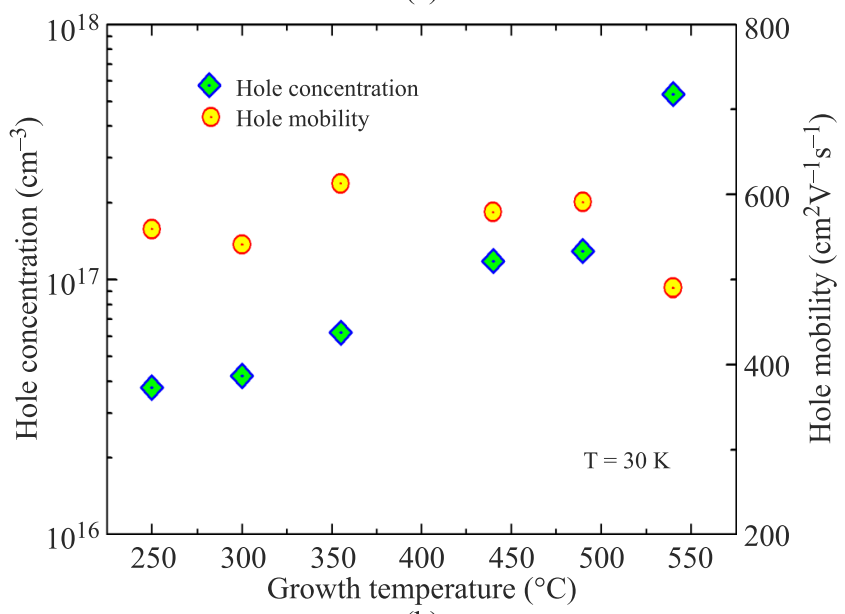

(b)

Fig. 4. The GaSb epilayer's hole concentration and hole mobility as a function of growth temperature measured at $80 \mathrm{~K}$ (a) and room temperature (b). 


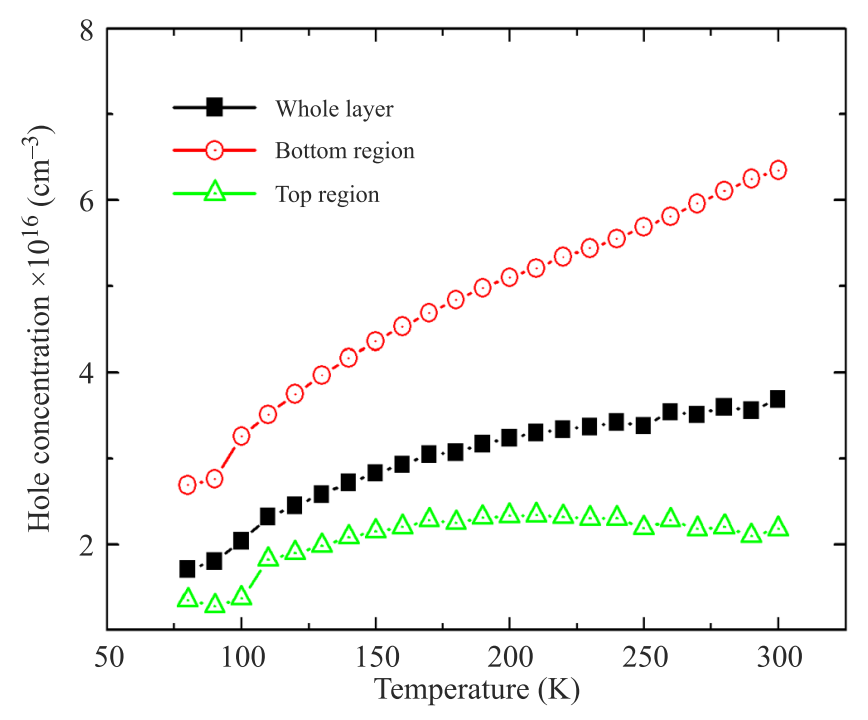

Fig. 5. The differential Hall measurement of a 5- $\mu \mathrm{m}$ thick GaSb layer grown at $300^{\circ} \mathrm{C}$, with a $5 \mathrm{Sb} / \mathrm{Ga}$ flux ratio. The etched thickness is $2.5 \mu \mathrm{m}$.

As a result, the hole concentration increases when the growth temperature ramps without suitable compensation by an increased $\mathrm{Sb} / \mathrm{Ga}$ flux ratio. On the contrary to the previous work, we had the lowest hole concentration at very low temperature; $3.78 \times 10^{16} \mathrm{~cm}^{-3}$ and $1.8 \times 10^{16} \mathrm{~cm}^{-3}$ for a $2-\mu \mathrm{m}$ thick $\mathrm{GaSb}$ layer grown at $250^{\circ} \mathrm{C}$, and a $5-\mu \mathrm{m}$ thick $\mathrm{GaSb}$ layer grown at $300^{\circ} \mathrm{C}$, respectively.

Lower hole concentrations were obtained by other groups. Y. Li et al. [18] reported on $1.63 \times 10^{16} \mathrm{~cm}^{-3}$ room temperature hole concentration at growth temperature of $490^{\circ} \mathrm{C}$, while M. Lee et al. [25] had $7.8 \times 10^{15} \mathrm{~cm}^{-3}$ at growth temperature $550^{\circ} \mathrm{C}$. A growth rate of $1 \mu \mathrm{m} / \mathrm{h}$ was used by the two previous groups.

Excessive hole concentration in the layers grown by us was probably due to the non-optimized low temperature growth conditions resulting in formation of structural defects, especially in vicinity to GaAs substrate - GaSb interface.

In order to study the variation of the hole concentration along the GaSb layer, the differential Hall measurement was performed. The measured GaSb layer had a thickness of $5 \mu \mathrm{m}$, grown at $300^{\circ} \mathrm{C}$ with $5 \mathrm{Sb} / \mathrm{Ga}$ flux ratio. Figure 5 shows the hole concentrations for the bottom and top regions, as well as that for the whole layer. The first-to-grow region of the layer shows significantly higher hole concentrations and large activation energy. Moreover, the hole concentration in the bottom part of the GaSb layer increases with temperature ramp, in contrast to the top region layer. This is an indication of different type of the defects in the bottom and upper layers.

Figure 6(a) shows the FWHM and room temperature hole concentration of GaSb epilayers as a function of the growth temperature. The growth temperature $440^{\circ} \mathrm{C}$ seems to be the best parameter to get relatively low hole concentration and proper crystal quality at the same time. To investi-

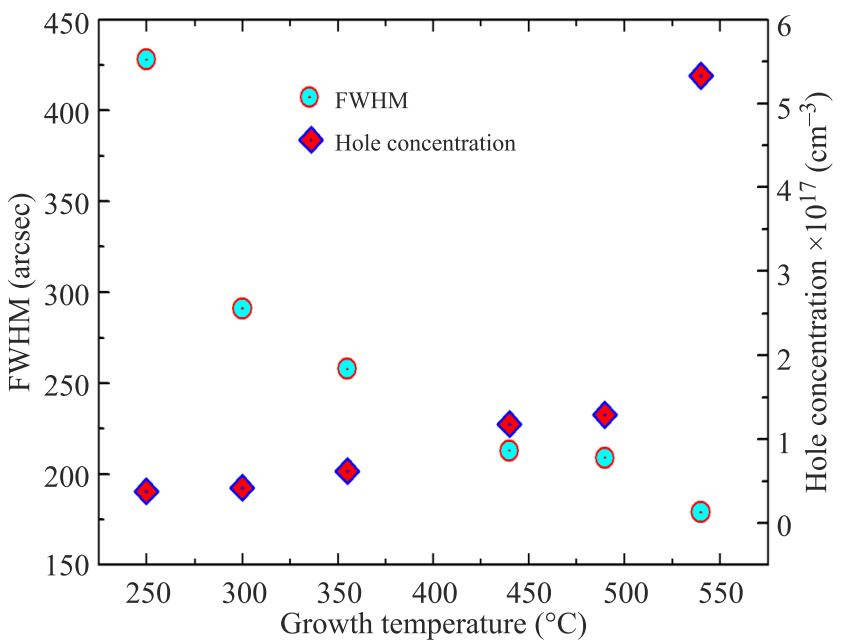

(a)

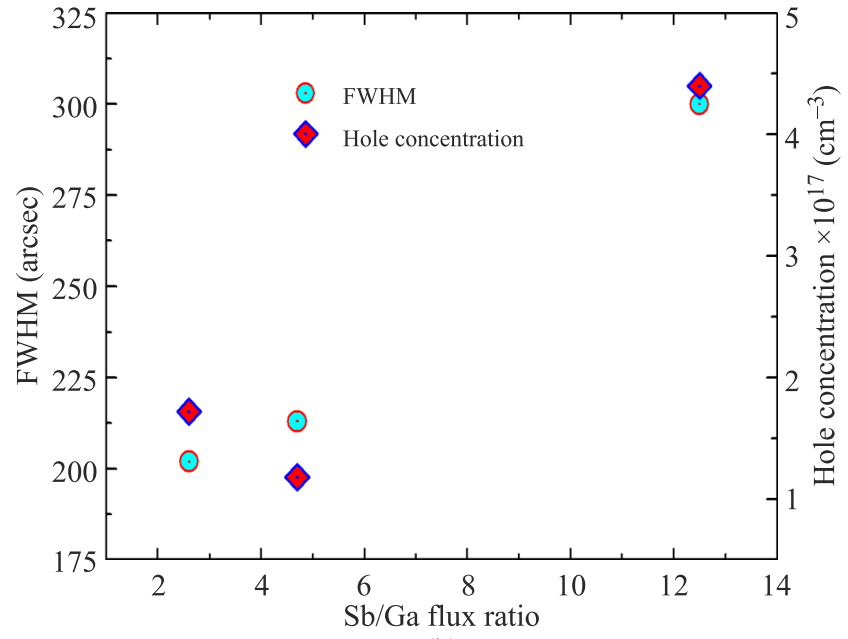

(b)

Fig. 6. FWHM and room temperature hole concentration for 2- $\mu \mathrm{m}$ thick GaSb epilayers vs. growth temperature (a) and versus $\mathrm{Sb} / \mathrm{Ga}$ flux ratio at growth temperature of $440^{\circ} \mathrm{C}(\mathrm{b})$.

gate the influence of the $\mathrm{Sb} / \mathrm{Ga}$ flux ratio, three $\mathrm{GaSb}$ epilayers were grown at $440^{\circ} \mathrm{C}$ with selected $\mathrm{Sb} / \mathrm{Ga}$ flux ratios.

Figure 6(b) shows the FWHM and the room temperature hole concentration of $\mathrm{GaSb}$ epilayers as a function of a $\mathrm{Sb} / \mathrm{Ga}$ flux ratio. When the $\mathrm{Sb} / \mathrm{Ga}$ flux ratio increases from 2 to 5 , crystalline quality improves and at the same time, the hole concentration decreases down to $1.18 \times 10^{17} \mathrm{~cm}^{-3}$. Further increase of $\mathrm{Sb} / \mathrm{Ga}$ flux ratio results in the deterioration of crystalline quality and a large hole concentration.

\section{Summary and conclusions}

Undoped GaSb epilayers were grown on GaAs substrates. The influence of the growth temperature and the $\mathrm{Sb} / \mathrm{Ga}$ flux ratio on GaSb epilayers' surface morphology, crystalline quality, hole concentration and mobility was investigated with optical microscopy, $\mathrm{X}$ ray diffractometry and Hall measurements. Shiny mirror-like GaSb epilayers 
were grown with growth rate of $0.66 \mu \mathrm{m} / \mathrm{h}$ under optimized $\mathrm{Ga}$ and $\mathrm{Sb}$ fluxes at temperatures ranging from $250^{\circ} \mathrm{C}$ to $540^{\circ} \mathrm{C}$.

The X-ray measurements shows steady improvement of crystalline quality with the increase of growth temperature from $250^{\circ} \mathrm{C}$ to $540^{\circ} \mathrm{C}$ with suitable choice of $\mathrm{Sb} / \mathrm{Ga}$ flux ratio. This finding is confirmed by larger Hall effect mobility in the layers grown at higher temperatures. The poor quality of layers grown at low temperatures are probably due to the formation of extended defects in the material, especially when growth rate is too large for the low growth temperature.

All the layers show p-type conductivity over 80 to $300 \mathrm{~K}$ temperature range due to $\mathrm{Ga}$ and $\mathrm{Sb}$ antisites. The hole concentration tends to drop with decreasing temperature. The lowest concentration $\left(3.78 \times 10^{16} \mathrm{~cm}^{-3}\right)$ was measured in the layers grown at $250^{\circ} \mathrm{C}$, unfortunately of low crystalline quality.

Differential Hall measurements revealed increased hole concentration in the bottom part of the layers interfacing GaAs substrates, characterized by a high dislocation density.

We expect the growth of high quality layers with low native defects' concentration can be accomplished at elevated temperatures and with more careful optimization of the $\mathrm{Sb} / \mathrm{Ga}$ ratio.

\section{Acknowledgement}

This paper has been completed with the financial support of the Polish National Science Centre, Project: UMO-2012/07/ D/ST7/02564.

\section{References}

1. B.R. Bennet, R.Magno, J.B. Boos, W. Kruppa, and M.G. Ancona, "Antimonide-based compound semiconductors for electronic devices: A review", Solid-State Electron. 49, 1875-1895 (2005).

2. L. Desplanque, D. Vignaud, and X. Wallart, "High mobility metamorphic AlSb/InAs heterostructures grown on InP substrates", J. Cryst. Growth. 301-302, 194-198 (2007).

3. Y. Li, Y. Zhang, and Y. Zeng, "Electron mobility in modulation-doped AlSb/InAs quantum wells", J. Appl. Phys. 109, 073703 (2011).

4. L. Shterengas, G.L. Belenky, A. Gourevitch, D. Donetsky, J.G. Kim, R.U. Martinelli, and D. Westerfeld, "High-power $2.3 \mu \mathrm{m}$ GaSb-based linear laser array", IEEE Photonics Technol. Lett. 16, 2218-2220 (2004).

5. C. Mourad, D. Gianardi, K.J. Malloy, and R. Kaspi, " $2 \mu \mathrm{m}$ $\mathrm{GaInAsSb} / \mathrm{AlGaAsSb}$ midinfrared laser grown digitally on GaSb by modulated-molecular beam epitaxy", J. Appl. Phys. 88, 5543 (2000).

6. H.K. Lin, D.W. Fana, Y.C. Lina, P.C. Chiua, C.Y. Chiena, P.W. Lia, J.I. Chyia, C.H. Kob, T.M. Kuanb, M.K. Hsiehb, W.C. Leeb, and C.H. Wann, "E-beam-evaporated $\mathrm{Al}_{2} \mathrm{O}_{3}$ for InAs/AlSb metal-oxide-semiconductor HEMT development", Solid-State Electron. 54, 505-508 (2010).
7. E.H. Aifer, J.G. Tischler, J.H. Warner, I. Vurgaftman, W.W. Bewley, J.R. Meyer, J.C. Kim, L.J. Whitman, C.L. Canedy, and E.M. Jackson, "W-structure type-II superlattice long-wave infrared photodiodes with high quantum efficiency", Appl. Phys. Lett. 89, 053519 (2006).

8. O. Cathabard, R. Teissier, J. Devenson, J.C. Moreno, and A.N. Baranov, "Quantum cascade lasers emitting near 2.6 нm”, Appl. Phys. Lett. 96, 141110 (2010).

9. Y.C. Xin, L.G. Vaughn, L.R. Dawson, A. Stintz, Y. Lin, L.F. Lester, and D.L, Huffaker, "InAs quantum-dot GaAs-based lasers grown on AlGaAsSb metamorphic buffers", Appl. Phys. Lett. 94, 2133 (2003).

10. P. Jayavel, S. Nakamura, T. Koyama, and Y. Hayakawa, "Effects of buffer layer on the structural and electrical properties of InAsSb epilayers grown on GaAs (001)", Phys. Stat. Sol. C3, 2685-2688 (2006)

11. H.S. Kim, Y.K. Noh, M.D. Kim, Y.J. Kwon, J.E. Oh, Y.H. Kim, J.Y. Lee, S.G. Kim, and K.S. Chung, "Dependence of the AlSb buffers on GaSb/GaAs (001) heterostructures", $J$. Cryst. Growth. 301-302, 230-234 (2007).

12. K. Akahane, N. Yamamoto, S. Gozu, and N. Ohtani, "Heteroepitaxial growth of $\mathrm{GaSb}$ on $\mathrm{Si}(001)$ substrates", J. Cryst. Growth. 264, 21-25 (2004).

13. R.T. Hao, S.K. Deng, L.X. Shen, P.Z. Yang, J.L. Tu, H. Liao, Y.Q. Xu, and Z.C. Niu, "Molecular beam epitaxy of GaSb on GaAs substrates with AlSb/GaSb compound buffer layers", Thin Solid Films. 519, 228-230 (2010).

14. A. Jallipalli, G. Balakrishnan, S.H. Huang, A. Khoshakhlagh, L.R. Dawson, and D.L. Huffaker, "Atomistic modeling of strain distribution in self-assembled interfacial misfit dislocation (IMF) arrays in highly mismatched III-V semiconductor materials", J. Cryst. Growth. 303, 449-455 (2007).

15. J. Tatebayashi, A. Jallipalli, M.N. Kutty, S.H. Huang, G. Balakrishnan, L.R. Dawson, and D.L. Huffaker, "Room-temperature lasing $1.82 \mu \mathrm{m}$ of $\mathrm{GaInSb} / \mathrm{AlGaSb}$ quantum wells grown on GaAs substrates using an interfacial misfit array", Appl. Phys. Lett. 91, 141102 (2007).

16. W. Qian, M. Skowronski, R. Kaspi, M. De Graef, and V.P. Dravid, "Nucleation of misfit and threading dislocations during epitaxial growth of GaSb on GaAs (001) substrates", $J$. Appl. Phys. 81, 7268 (1997).

17. A. Jallipalli, G. Balakrishnan, S.H. Huang, T.J. Rotter, K. Nunna, B.L. Liang, L.R. Dawson, and D.L. Huffaker, "Structural analysis of highly relaxed GaSb grown on GaAs substrates with periodic interfacial array of $90^{\circ}$ misfit dislocations", Nanoscale Res. Lett. 4, 1458-1462 (2009).

18. Y. Li, Yang Zhang, Yuwei Zhang, B. Wang, Z. Zhu, and Y. Zeng, "Molecular beam epitaxial growth and characterization of GaSb layers on GaAs (001) substrates", Appl. Surface Science. 258, 6571-6575 (2012).

19. C. Anayama, T. Tanahashi, H. Kuwatsuka, S. Nishiyama, S. Isozumi, and K. Nakajima, "High-purity GaSb epitaxial layers grown from Sb-rich solutions", Appl. Phys. Lett. 56, 239 (1990).

20. G.R. Johnson, B.C. Cavenett, T.M. Kerr, P.B. Kirby, and C.E.C. Wood, "Optical, Hall and cyclotron resonance measurements of GaSb grown by Molecular Beam Epitaxy", Semicond. Sci. Technol. 3, 1157-1165 (1988).

21. E.T.R. Chidley, S.K. Haywood, A.B. Henriques, N.J. Mason, R.J. Nicholas, and P.J. Walker, "Photoluminescence of GaSb 
grown by metal-organic vapour phase epitaxy", Semicond. Sci. Technol. 6, 45-53 (1991).

22. D. Effer and P.J. Etter, "An investigation into the apparent purity limit in GaSb", J. Phys. Chem. Solids. 25, 451-460 (1964).

23. M. Ichimura, K. Higuchi, Y. Hattori, T. Wada, and N. Kitamura, "Native defects in the $\mathrm{Al}_{\mathrm{X}} \mathrm{Ga}_{1-\mathrm{x}} \mathrm{Sb}$ alloy semiconductor", J. Appl. Phys. 68, 6153 (1990).
24. Q.H. Xie, J.E. Van Nostrand, R.L. Jones, J. Sizelove, and D.C. Look, "Electrical and optical properties of undoped $\mathrm{GaSb}$ grown by molecular beam epitaxy using cracked $\mathrm{Sb}_{1}$ and $\mathrm{Sb}_{2}$ ", J. Cryst. Growth. 207, 255-265 (1999).

25. M. Lee, D.J. Nicholas, K.E. Singer, and B. Hamiltom, "A photoluminescence and Hall-effect study of GaSb grown by molecular beam epitaxy", J. Appl. Phys. 59, 2895 (1986). 